\title{
The Effectiveness of Kano-QFD Approach to Enhance Competitiveness of Technology-Based SMEs through Transfer Intention Model
}

\author{
Yun Hwangbo ${ }^{1}$, Young-Seok Yang ${ }^{2}$, Myung-Seuk Kim ${ }^{2}$ and YoungJun Kim ${ }^{3, *}$ \\ 1 Graduate School of Global Entrepreneurship, Kookmin University, Seoul 02707, Korea; \\ yun88@kookmin.ac.kr \\ 2 Graduate School of Entrepreneurial Management, Hanbat National University, Daejeon 34158, Korea; \\ ytony@hanbat.ac.kr (Y.-S.Y.); kmsjws@hanbat.ac.kr (M.-S.K.) \\ 3 Graduate School of Management of technology, Korea University, Seoul 02841, Korea \\ * Correspondence: youngjkim@korea.ac.kr; Tel.: +82-2-3290-4872
}

Received: 31 July 2020; Accepted: 19 September 2020; Published: 23 September 2020

\begin{abstract}
Despite the value of QFD (Quality Function Deployment), it has been applied to individual industries, or only to large companies with sufficient QFD-related human resources and sufficient financial resources. Most SMEs, which account for $80 \%$ of the world economy, have not been able to benefit from QFD, the tool designed to revamp the growth, due to the lack of financial and human resources to implement QFD and Kano Model. This paper is brought to assess the effectiveness of Kano-QFD approach for technology-based SMEs through the transfer intention model. In order to verify the effectiveness of the above approach, 860 technology-based SMEs in their establishment 3-7 years are researched for the learning transfer intention after the completion of Kano QFD education and training program. The results of this study are that the perceived content validity has the direct effect on learning transfer intention simultaneously with the partial mediating effect through the self-efficacy factor. The learner readiness does not directly influence the learning transfer intention and the self-efficacy completely mediates the learner readiness and the transfer intention. This research contributes to providing critical implications for the educators and training planners in in private sector as well as policy makers of technology-based SMEs in the public sector.
\end{abstract}

Keywords: new technology-based firms (NTBFs); quality function deployment; effectiveness of Kano QFD; transfer intension; training performance; learner readiness; perceived content validity; self-efficacy; SMEs

\section{Introduction}

Small and medium-sized enterprises (SMEs) are the backbone of the economy in most countries [1] and account for $80 \%$ of the world economy [2]. Many scholars and government officials around the world recognize that most of the newly created jobs are from entrepreneurial startup companies rather than large companies. The phenomenal growth of mobile platforms and new ICT technologies that we observe today have strong venture capital characteristics, supported intensively by the venture capital industry [3,4]. Technology entrepreneurial firms, such as technology-based SMEs 3-7 years since their inceptions, contribute to new growth dynamics in the country, boost the direct and indirect employment, and enable wealth creation and the sophistication of local industries [5-7].

The growth outlook for SMEs, however, is not encouraging. According to the survey conducted by the Government of Korea, the average-based sales and net income tend to remain stagnant in technology-based SMEs 3-7 years after their birth [8]. The survival rate at their third year of Korean companies is inferior to those of developed countries [9]. The Government of Korea has initiated variety 
of support programs for years to increase the competitiveness and survival rate of the technology-based SMEs, whose results prove rather dismal. The survival rate of the companies lowered even further, and the growth potential of the companies has no significant impact [10]. There emerges the strong need for specially designed programs for technology-based SMEs in 3-7 years to unlock the growth potentials and deal with stagnant net incomes in the grand vision to drive economic and national growth with highly competitive enterprises.

The goal of QFD is to achieve more profitability by systematically integrating customer needs identified to achieve customer satisfaction into the product or service development processes [11]. This makes QFD recognized as a convenient product development method that can maximize customer satisfaction [12,13]. In particular, the first advantages of QFD are that it enables an organization to form a culture that focuses on "quality of product or service" and "customer" [14]. Second, it enables us to accurately understand consumer needs, which are important issues for the success of companies in the era of the Industry 4.0. Third, QFD has the advantage of connecting consumers' needs effectively with products or services, so this will lead directly to the improved competitiveness of the company.

Looking at these merits of QFD, it is logically ideal to apply OFD as a government funded support program to such technology-based SMEs in the crisis of stagnating sales and net incomes without ample resources at their disposable. Systematically integrating the needs of consumers in the design of products is a paramount focus for the companies of any sizes, but more critical to especially small and medium-sized enterprises (SMEs) without sufficient technical means and resources [1]. The heart of QFD is in the integration of marketing, design technology, and manufacturing function in the process of designing a product to reflect customer needs and preferences [15]. In this vein, QFD can be easily fit for SMEs where small number of talent teams across marketing, technology design, and manufacturing work closely together. QFD, however, requires sophisticated processes and qualified professionals to proceed, which prevent SMEs in limited financial and human resources from considering implementing QFD and Kano Model. [16].

Against this background, in this study, we present an education and training program that can comprehensively incorporate QFD, that has been used only for individual companies of some industries, into technology-based SMEs of various industries. This program will be leveraged as a one of measures to solve the sales and net profits stagnation of technology-based SMEs in 3-7 years of establishment in the stage of the initial growth period of companies. We research to prove the effectiveness of these programs. In order to verify the effectiveness of the program, we would like to investigate the factors that influence the learning transfer intention and its path structure as well as the actual application of the learning to the field by the employees who participated in the trainings.

Tai [17] argued that the effectiveness of education and training is measured as the degree to which the purpose of education and training is achieved. The concept of education and training program evaluation is to present the information needed to improve the education and training program, to decide whether the program is sustainable or not and to indicate the extent to which relevant departments contribute to the organization's goals and objectives, while justifying the feasibility of the education and training program [18,19]. Therefore, in order to investigate the validity of the Kano QFD-based training program for enhancing the competitiveness of technology-based SMEs more than three years and less than seven years old, we apply conventional educational training effect measurement model and its measurement method.

Many prior studies support Kirkpatrick's hierarchical model as an evaluation method for education and training [17,20-23]. In Kirkpatrick's hierarchical education performance model, positive reactions and learning outcomes of education and training participants, changes in behavior due to the results of education and training, and job-related progress improvements can be expected when education and training programs are well-designed and well-administered. However, participant attitudes, interests, values, and expectations can undermine or enhance the effectiveness of education and training. Determining the characteristics of a particular individual that influences the effectiveness of education and training is very important when we want to find out how to increase the behavioral changes 
and the potential for performance gains from participating in educational training programs [23]. Therefore, this study focuses on the personal characteristics of education and training participants that influence the effectiveness of education and training, and in particular the learning transfer effect, which examines whether or not there is an intention to incorporate what has been obtained through education and training into the field.

The concept of learning transfer intention was first mentioned in the study by Magjuka and Baldwin [24]. They exploited the transfer intention in the concept of replacing an existing transfer motivation without the special definition for it. Also, Foxon [25] has played an important role in forming the concept of transfer intention. He presented through the model that the intention of transfer was the starting point just before starting the first step of transfer by subdividing the process of transfer of education and training. Intention is defined academically as "reflecting the cognition of an individual's will to perform a given action". The behavioral intention is the closest distance when the actual behavior is expressed in Ajzen's planned behavior theory [26], which is the typical in the field of psychological behavior, and it is treated as an important factor for predicting the actual behavior.

The three types proposed by Baldwin and Ford [27] have been accepted as the most influential conceptual models to date as factors affecting the learning transfer intention [28]. The three factors are classified into trainee characteristics, training design, and work environment. This study is aimed at employees who participated in the training courses of this program to verify the effectiveness of the program that can be comprehensively applied into technology-based SMEs of various industries in order to enhance the competitiveness of them and so only trainee characteristics and training design among the three types of Baldwin and Ford [27] were selected. Work environment will be dealt with in the subsequent studies, and the limitations of the studies will be mentioned. The comprehensive QFD effectiveness studies do not exist to the best of the authors' knowledge. This research is to empirically prove the effectiveness of QFD with the large number of CEOs as the actual trainee in their respective companies, which differentiate from most previous studies done in a single industry or in the case study approach [29,30]. Christiano et al. [31] also pointed out that only the use status of QFD was described in the survey results of the Japan Quality Control Association, and no information was provided regarding the effectiveness of QFD. In other words, we present a QFD program method to help improve the competitiveness of technology-based SMEs more than three years and less than seven years old in various industries, while QFD has been traditionally used mainly within individual industries, and we verify the effectiveness of QFD instead of just a QFD case study. The second differentiation is to provide the theoretical basis on how to practically support technology-based SMEs in 3 7 years after the foundation for improving their competitiveness in addition to financial support through this empirical verification research. In doing so, this study offers real world examples of Kano-QFD effectiveness at large scale, which enriches the Kano-QFD researches. Studying SMEs, which are underserved in Kano-QFD studies, is an additional theoretical contribution of this paper. This research would be a great contribution to present alternatives to the current policy making for policy makers and specialists in relevant organizations by investigating the validity of the Kano QFD training program, designed to solve the stagnant sales and net profit of 3-7-year-old technology-based SMEs, which is expected to enhance the effectiveness of government's technology-based SMEs support project as well.

\section{Theory and Hypotheses}

\subsection{QFD and Kano Model}

QFD (Quality Function Deployment) is a holistic concept that translates customer needs into appropriate technical requirements and provides each step method for production and development of each product, thus the whole department is to cooperate closely, such as marketing strategy, planning, product design, engineering, product development, and sales department, etc. [30]. There is also a definition [32] that "QFD is a method for an organization to predict customer needs, prioritize them, 
and to effectively embody the products or services which would be provided to the end consumer. Bicknell and Bicknell [33] defined QFD as "a systematic approach that measures customer needs using objective and quantified methods and translates them into product and process factors that can be unambiguously identified."

"Quality" in "Quality Function Deployment" means quality, features, or attributes of a product, "function" means a function or mechanization, and "deployment" means diffusion, development, deployment, or evolution [34].

According to Runte [35], "quality" is used to mean "attributes", and the attributes that are the most important are investigated first and are the basis for other attributes are the attributes requested by customers among the attributes that appear in QFD. "Function" means "various functions within an organization"; for example, it is a function of a subordinate organization such as marketing, engineering, manufacturing, and purchasing part that forms and implements quality of products. "Development" means "to put or distribute widely for future use", and technically it can be used in a narrower sense. It is said that a selected portion of the vertical attributes of the first matrix of the QFD called the House of Quality is used as the input element for the second matrix, the part of the vertical attribute, which is partly attributed to the second matrix and is used as the input element of the next matrix. In this way, the fact that QFD data are applied to both functions of the organization through the QFD process is said to be "deployed".

Thus, QFD is created to connect design, development, engineering, marketing, manufacturing, services, and other organizational functions with the desired quality of the customer's expectations through a systematic arrangement that seeks to mitigate the growing demand differences between producers and users in the process of manufacturing and business development [36].

Recently, QFD has been very closely associated with concurrent engineering and Lean Production, which emphasizes product quality and innovation [37,38].

According to Tan and Shen [39], QFD was invented and presented as a quality technique in 1966 by Yoji Akao in Japan. QFD was applied for the first time in 1972 at Mitsubishi Heavy Industries' Kobe shipyard when making deep-sea fishing boats [40], and Toyota Motor Corporation in 1975 has begun to apply it to the automobile industry, beginning to be applied to all industries.

QFD has been introduced by global companies such as Ford, GM, Hewlett Packard, AT\&T, and ITT in the United States since the mid-1980s, with great success, and it was mainly used in the field of manufacturing, but gradually the scope of application has been expanded and applied not only to industry but also to the fields of administration and services [41].

Regarding the effect of introducing QFD, Toyota Motor Corporation has reflected the needs of various customers in its products, and since 1984, Toyota's pre-mass injection cost has been $61 \%$ compared to 1977, which was the time before the introduction of QFD. It was found that the input cost before mass production was reduced by $61 \%$ compared to 1977 , which was the time before the introduction of QFD, the time until market shipment was shortened to about one-third, and the product quality was improved [30].

The QFD and Kano Model are complex and require professionals to run them, so they have been done by large companies with resources and qualified professionals [16]. Cristiano et al. [31] reports that $30 \%$ of the 400 companies selected by the supporting members of the Japanese Union of Scientists and Engineers responded to the e-mail survey and it takes a meaningful period of six years for them to settle QFD in their organization, taking two years to systematize this. They also explain that the most important impediment to performing QFD is the ability to capture and understand customer needs and complete a large QFD matrix.

Looking at the current situation of QFD utilization through open literature, it has been used in various fields and industries such as construction, communication, aircraft, horticulture, clothing, medical service, food, library, university education, milk, postal service, petrochemistry, VR/AR, Mobile-Government Service, Logistics Service, Tire, and IOT. Also, it can be confirmed that QFD is applied from various countries such as the United States, South Korea, Italy, China, Pakistan, United 
Kingdom, Spain, Indonesia, India, Iran, The Netherlands, UAE, and Turkey through the literature. An average of approximately 350 documents has been published annually from 2015 to 2020 when searching the number of documents such as cases utilizing QFD through Web of Science, Elsevier, Scopus, etc.

Sharma et al. [42] investigated 400 documents with a QFD theme applied from 1988 to 2006 and divided them into the categorical functional fields of QFD and the pure QFD (pure QFD) research field. The categorical functional fields are categorized into primary, secondary, and tertiary. The primary functional fields consisted of product development, customer requirement analysis, and quality management system. The secondary functional fields are concurrent engineering, management science, planning, operational research, education, software, and specialized systems fields such as artificial intelligence (AI), artificial neural networks (ANN), and fuzzy logic. The tertiary fields are further expanded by the application of QFD, for example, in the areas of construction and housing, cost, environment, decision making, and services sector application.

Looking at the literature on the shortcomings of QFD, four issues can be summarized [43]. The first is that traditional QFD cannot be used when multi-criteria considerations are needed [44]. The second is that using customer's terminology leads to ambiguity and inaccurate characteristics, raising questions about the validity of QFD results $[45,46]$. Thirdly, QFD is mainly useful only for new products and is not well utilized for improving existing products $[47,48]$. Fourth, QFD is complex and very difficult to perform while analysis of the data is performed from a subjective point of view; thus, results are lacking in consistency, leading to the concerns on the vague relationship displayed between customer needs (Whats) and product specifications (Hows) $[46,49,50]$. The advanced models developed to solve the limitations of traditional QFD have been proposed such as Fussy QFD, Kano-based QFD, AHP QFD, ANP QFD, Project QFD, and TQFD [51].

The quality research section of the Japan Quality Control Association conducted the most extensive survey on the actual state of QFD use among Japanese companies Also, in 1986 [52,53], the survey was conducted by e-mail to more than 400 companies in Japan selected by the supporting members of the Japanese Union of Scientists and Engineers (JUSE). According to the survey results, $30 \%$ of the respondents applied QFD widely to multiple products, and the House of Quality was the most used matrix. However, the results of the study only described the use situation of QFD and did not provide any information about the effectiveness of QFD [41].

In addition, there is a limit to how best practice research remains in the country, mainly to case studies and research studies [41] while QFD has been used extensively in a variety of industries worldwide [29,30]. Franceschini and Terzago [54] also points out that the effectiveness of training courses is not handled, only staying in case studies despite the new approach to applying QFD to industrial training courses. An analysis of prior research shows that QFD is applied to various fields, such as the manufacturing industry, service industry, and even public services, but most of the studies are limited to cases in an individual industry. In addition, few studies have tried to analyze the feasibility of application results and only presented application cases of QFD. This research verifies the effectiveness of QFD after applying it comprehensively to the technology-based SMEs in various industries in order to overcome the limitation $[41,54]$ of the verification absence of the effectiveness of QFD, which differentiated this paper from the existing studies focusing on only a case of the single industry.

Traditional QFD analysis has been a difficult problem to understand accurately for customer needs [55] as explained on the shortcomings of QFD [43]. Researchers have combined QFD with Kano's Model for customer satisfaction over the years in order to accurately understand customer requirements [36,56-59]. Kano Model is a Customer Satisfaction measurement model studied by Noriaki Kano of Tokyo Rica University in Japan in 1984 [40].

The Kano Model has been applied to classify the characteristics of a product or service and used as a way to satisfy the needs of its customers since being developed by Kano and his colleagues [60]. The Kano Model has also been widely applied in several industries with an effective tool for examining 
customer preferences [61]. Lee et al. [62] applied the Kano Model to QFD to confirm the needs of consumers. Shen et al. [63] insist on a customer delight element to provide an innovative product that brings higher consumer satisfaction than the competitor while presenting an innovative product development process and on applying the Kano Model utilizing questionnaire in the QFD process.

In this study, the QFD training program is enabled for technology-based SMEs to confirm their customers' needs and lead to sales expansion because the Kano Model is used when investigating customer requirements. They can find the customer delight factor, that is, the attractive quality factor, so that the technology-based SMEs can have a competitive advantage with their competitor in the market through the Kano Model, and gain the market share more than the competitor. The reason that the customer delight factor is important for the technology-based SMEs is that they lack resources; not only human resources but also brand power compared to their competitors. Those customer delight factors generate an effect of impressing a customer and attracting another customer by the customer when the firm penetrates into the market. Therefore, it becomes possible to outperform competitors and survive in the market when factors of customer delight are dissolved in products or services.

\subsection{Application QFD for SMEs}

As stated by the European Commission [64], SMEs are companies that employ less than 250 employees and of which the annual turnover is less than 50 million euros or of which the total assets are less than 43 million euros. The definition of SMEs in South Korea is that SMEs require maximally 109 million euros or less average sales or annual sales depending on the type of industry for enterprises that conduct business for the purpose of profit, and total assets without industry classification must be less than 364.9 euros as stated by Framework Act on Small and Medium Enterprises Article 2 Paragraph 1 Item 1 [65]. It is about double the turnover and about eight times the total assets, compared to European standards.

SMEs are the backbone of the economy in most countries. In addition, systematically integrating the needs of consumers in the design of products is an important issue for all industries, especially SMEs with insufficient technical means and resources [1]. According to Zhou et al. [16], most SMEs, which account for $80 \%$ of the global economy [2], have insufficient financial resources and experts who carry out QFD and Kano Model in them, so there is a limit to applying it to them. Therefore, they propose to convert and use Customer Requirement (CRs) in a way called Customer Requirement Information (CRIs) for easy and proper application to SMEs. However, if an expert who is basically familiar with the basic structure of QFD does not work for SMEs, QFD cannot be utilized even if the customer's requirements are simply converted into customer requirement information.

There are relatively few studies applying QFD to SMEs. A total of almost 50 journal papers from 2001 to 2019 have been published when the QFD and SMEs are commonly searched and displayed documents that utilize QFD for SMEs through the Web of Science, Elsevier, Scopus, etc. This is a very small number when compared with the publication of more than 350 QFD-related studies each year. In addition, cases of SMEs in India, China, Malaysia, Singapore, and Hong Kong, which are mainly in Asia, have been announced.

Rozar et al. [66] applied QFD to promote Green Supply Chain Management and applied it to Malaysian SMEs for Sustainability performance approach, and O'Gorman et al. [67] applied QFD for the design and manufacture of innovative hybrid doors for SMEs. Hsu et al. [68] applied QFD to SMEs to overcome the limitations that SMEs have shortages of resources in most cases (unlike large enterprises, as successful sustainable enterprises) and to search for Balanced scorecard factors that meet sustainability development requirements through using QFD and fuzzy MADM (Multiple Attribute Decision-Making). QFD was applied to the e-business planning system for SMEs in the research of Tan et al. [69], and Barad and Gien [70] utilized QFD as a tool to help priority selection of SMEs to improve their performance. 
Looking at the above literature comprehensively, the papers that apply QFD to SMEs are mainly the case studies where they are limited in each industry, as are the cases with the existing QFD researches. Especially, there is a tendency to concentrate on sustainable enterprises and supply chain management. However, there is no research that presents a QFD utilization method that is structured to suit SMEs and early technology-based SMEs or that should be used in common with various types of SMEs and early technology-based SMEs.

In this research, one QFD professional coach is arranged per early technology-based SMEs in order to solve the problem that QFD is complicated and difficult, which has been pointed out as a limitation point in applying QFD to SMEs in the previous research. Also, we utilize Kano-based QFD to improve the ambiguity of customer requirements priority accuracy. Moreover, we verify the effectiveness of the Kano QFD training program applicable to early technology-based SMEs that can be used not only in one industrial field but also in various industrial fields.

\subsection{Effectiveness of Training Program}

Tai [17] argued that the effectiveness of training was the extent to which the purpose of training was achieved. The concept of training program evaluation is to present the information necessary to improve the training program, to decide whether the program is sustainable, to show how the relevant departments contribute to the organization's goals and objectives, and to justify the feasibility of the training program $[18,19]$. Based on these theoretical backgrounds, we apply a model that measures the effect of training to verify the effectiveness of the Kano QFD program applied to early technology-based SMEs in this study.

Training effectiveness is usually determined by some combination of categories presented in Kirkpatrick's [71] hierarchical model of training outcomes [23]. The Kirkpatrick model consists of four stages. Reaction assessment, which is the first step, is a measure of the degree of reaction of the program content and the training course of the people participating in the curriculum. Also, it aims to measure the satisfaction of participants through the step, which is "reaction evaluation" to investigate for lecture evaluation and course summary at educational sites. This step consists of evaluation items for correcting and supplementing educational process and operational problems rather than evaluating the effects and outcomes of education. The second evaluation of learning measures the change of the learner's attitude, the degree of knowledge acquired, and the degree of acquisition of technology as a result of the curriculum. The third step evaluation is a behavior evaluation, which is an evaluation of whether or not what the participants learned through the training process caused a change in the actual execution of duties, and usually the in-service applicability is evaluated. The final fourth step is to evaluate the results and whether there are any specific improvements to the individual or organization. For example, it evaluates substantial changes such as sales increase, cost reduction, productivity improvement, and profit increase. Reaction evaluation, learning evaluation, and behavior evaluation is an assessment of an individual who has undergone a training course, and result evaluation is to evaluate the effect of the results of the curriculum at the individual/organizational level on the business performance $[10,17,23]$.

Many prior studies support Kirkpatrick's hierarchical model as an evaluation method for education and training [17,20-23]. Although Alliger and Janek [72] criticized the suitability of relationships in measuring the four-step Kirkpatrick model [17], the Kirkpatrick model is still a useful and valuable method in evaluating the results of education and training [17,73-75].

Positive reactions and learning outcomes of participants, behavioral changes due to the results of the training, and progress improvement outcomes related to work can be expected when the training program is well designed and well-administered in Kirkpatrick's hierarchical evaluation model. However, the attitudes, interests, values, and expectations of participants can undermine or enhance the effectiveness of training. Determining the characteristics of a particular individual that affects the effectiveness of training is of great importance when we want to know how to increase the 
potential for behavioral changes and performance improvements that result from participating in a training program [23].

Therefore, this study focuses on the personal characteristics of training participants that influence the effectiveness of training, and in particular the learning transfer effect, which examines whether or not there is an intention to apply what has been obtained through the training into the field.

\subsection{Learning Transfer Intention Model}

The term "Learning transfer" was started in the concept of "transfer" in the 1910s and has been used as various terms such as education transfer and training transfer [76]. Many researchers have argued that "Motivation to Transfer" is one of the important factors that explain the learning transfer, and that it is an essential element in the process of training transfer [27,77,78]. Studies on the motives for transfer have been conducted continuously rather than studies on transfer intentions.

Motivation to Transfer is defined as the desire of learners or trainees to apply what they have learned through education and training to the field of work [23]. Yamnill and McLean [79] define transfer motivation as a participant's hope for using the knowledge and skills learned in the company training program on the job site. It may also define a transfer motivation as the intended effort to utilize the skills and knowledge learned through training in the field of actual work [80].

These definitions are expressed in a desire, hope, intended effort to emphasize the willingness of the learner. The concept of motivation to transfer has begun to be noticed in attempts to evaluate the effectiveness of training, and Kirkpatrick's four-level evaluation model has emerged and has been gradually materialized. The performance of training consists of reactions, learning, behaviors, and outcomes according to a Kirkpatrick's study [81], and the concept closely related to learning transfer among these is the behavior evaluation corresponding to the third step [76].

Rowold [82] argued that a participation in training will improve job outcomes in the future if learners are motivated to apply the content of the training to their work when they enter their work environment. Intention in the transfer intention means "the idea or plan to do what you want to do, or what you want to attempt," and is treated as an important factor in the academic domain of consumer behavior. Academically, it is defined as "reflecting the cognition of an individual's will to perform a given action" [76]. The behavioral intention when the actual behavior is expressed is treated as an important factor that predicts the actual behavior in the closest distance according to the representative theoretical planned behavior theory [26] in the field of psychological behavior [76].

The three types proposed by Baldwin and Ford [27] have been accepted as the most influential conceptual models to date as factors affecting the transfer intention. [28]. Three factors are classified into learner characteristic factors, training design factors, and work environment factors. This model includes various variables compared to the Holton model [83], and is used by many researchers [84].

In this study, we target CEOs or employees of 3-7-year-old technology-based SMEs who have participated in the Product Improvement Academy under the control of Ministry of SMEs and Startups of the South Korean government ministry in charge of SMEs and Korea Institute of Startup and Entrepreneurship Development of its affiliated organization. The learner characteristics factor and the design factor of training are selected as the two factors of the transfer intention impact factors among the three types proposed by Baldwin and Ford [27] in consideration of the peculiarity of this program.

Regarding the business environment factor, it is very difficult to select the measurement question, considering that the type of industry is different for each learner and the number of years since its foundation is different. So, we decided to mention it as the limits and the subsequent research in this study. We investigate the attitudes of learners to tackle learning as their readiness, that is, their motives and expectations for learner's characteristic factors. Based on these theoretical foundations, the first hypothesis is set as follows.

Hypothesis 1 (H1). A learner's readiness has effects on transfer intention. 
Self-efficacy, which is performance self-efficacy that gained from one's experience and surrounding feedback in relation to learning transfer ability, and the perceived content validity has the mediating effect on motivation to transfer in the learning transfer model of Kirwan and Birchall [85]. The term "Self Efficacy" means trust in one's ability, and is a concept developed by Bandura's theory of social learning [86]. Self-efficacy has been treated to be one of major factors in various research areas in terms of that a person with a high perception of self-efficacy can perform better than someone with the same level of knowledge and skill [84]. Therefore, the second hypothesis is set as follows.

Hypothesis 2 (H2). A learner's readiness has effects on self-efficacy.

The learner readiness is expressed as a direct effect on the transfer motivation, that is, the transfer intention, apart from self-efficacy in the model of Kirwan and Birchall [85], but the learner readiness and self-efficacy are set as the factors that influence the transfer motivation in the same way from the model of Holton III et al. [83]. Gegenfurtner et al. [78], in various studies investigating the relationship between self-efficacy and transfer motivation, put the focus of self-efficacy on "learning efficacy", "computer efficacy", and "general or execution self-efficacy", but he emphasizes post-training self-efficacy as the factor that most strongly explains the transfer motivation among them. Machin and Fogarty [87] ascertained the direct relationship between self-efficacy and transfer after training. It was Axtell et al. [88] and Al-Eisa et al. [89] who found that self-efficacy affects transfer intention in a general sense [84]. Therefore, the third hypothesis is set as follows.

Hypothesis 3 (H3). A learner's self-efficacy has effects on transfer intention.

There is insufficient empirical research to clarify what role the design factors of training play in the transfer process $[84,90]$. However, we decide to select the perceived content validity as a training design factor among the complicated factors of the learning transfer model of Kirwan and Birchall [85] in this study. Therefore, the fourth and fifth hypotheses are set as follows.

Hypothesis 4 (H4). A perceived content validity has effects on transfer intention.

Hypothesis 5 (H5). A perceived content validity has effects on self-efficacy.

As described above, self-efficacy has a mediating effect on the relationship between the perceived content validity and the motivation to transfer in the learning transfer model of Kirwan and Birchall $[84,85]$. We also select a self-efficacy as a mediating factor of learning transfer intention as in the study by Kirwan and Birchall [85]. Therefore, the sixth and seventh hypotheses are set as follows.

Hypothesis 6 (H6). A self-efficacy has mediating effects on the relationship between learner readiness and transfer intention.

Hypothesis 7 (H7). A self-efficacy has mediating effects on the relationship between perceived content validity and transfer intention.

Figure 1 shows the above hypothesis as a theoretical model. 


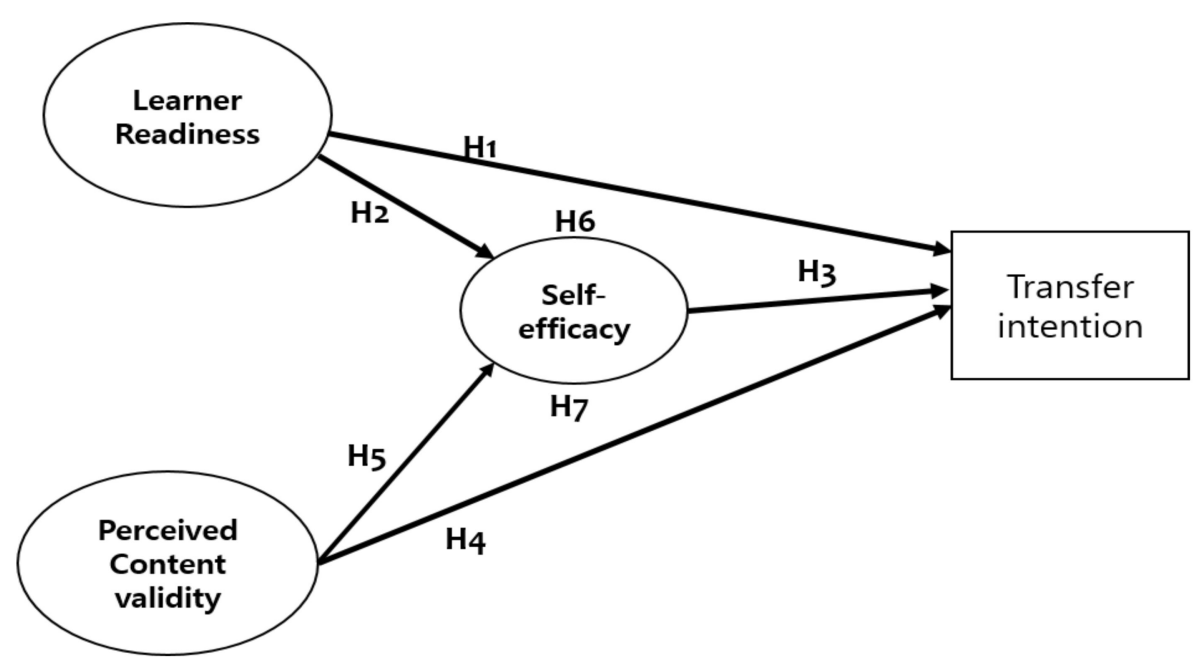

Figure 1. A theoretical model.

\section{Methods}

\subsection{Data Survey}

To obtain survey materials for this research, we distributed a questionnaire immediately after the training program to CEOs of SMEs, executives, and employees and utilize 860 copies of a sincere response questionnaire available among the participants in the Academy for Improvement of Products under the control of the Ministry of SMEs and Startups and Korea Institute of Start-up and Entrepreneurship Development, which were enforced in Chungcheong provice, Kyungsang province, Jeolla province, Gyeonggi province, and Seoul in Korea for 3-7-year-old technology-based SMEs from 19 May to 17 July 2017, from 21 May to 14 June 2018, and from 1 April to 27 June 2019. The reason for gathering survey data on transfer intention immediately after training is based on the fact that previous research considered that transfer intention had formed after training [76]. The range of industries analyzed in this study includes craft and design, mechanical and materials, bio and medical, energy and resources, electricity and electronics, information communication, and chemical fibers.

The operational definition of latent variable for this research is redefined according to the characteristics of the technology-based SMEs by referring to the Hwang and Gu's study [91] on the difference in effects of leadership training program between hospital and firm.

For the definition of learner readiness, Kirwan and Birchall [85] defined it as "the degree to which an individual was prepared to participate in training" based on Holton III et al.'s definition [83] and offered as an example of a measurement item: "Before the training, I thought training contents were suitable for the development of my work." We define the learner readiness as "an attitude that a training program would help the company grow and run its business," referring to Kirwan and Birchall's definition. The questionnaire items for measuring the variable are based on Hwang's learner readiness-related questionnaire items [92], which is also based on Holton II et al.'s model [75] and modified to be suitable for 3-7-year-old technology-based SMEs. Also, three items are deleted from the first items by the validity analysis and the reliability analysis, and six items suitable for the measurement variables of the latent variables are selected and measured on the Likert 5-point scale.

Perceived content validity is defined as "recognition that program content is associated with work" by Kirwan and Birchall's model of learning transfer [85]. Therefore, the perceived content validity of the training in this study is defined as "the degree to which the training content is relevant to one's work". The questionnaire items for measuring the variable are based on Hwang's perceived content validity-related questionnaire items [92], which is also based on Holton II et al.'s model [75] and modified to be suitable for 3-7-year-old technology-based SMEs. Also, seven items are deleted 
from the first 14 items by the validity analysis and the reliability analysis, and seven items suitable for the measurement variables of the latent variables are selected and measured on the Likert 5-point scale.

In the study by Kirwan and Birch [85], self-efficacy was defined as "confidence brought about from one's own experience and surrounding feedback in relation to learning and transfer ability". Therefore, we follow the definition above and the questionnaire items for measuring the variable are based on Hwang's self-efficacy-related questionnaire items [92], which is also based on Holton II et al.'s model [75], and modified to be suitable for 3-7-year-old technology-based SMEs. Also, three items, as in the first entry, suitable for the measurement variables of the latent variables are selected through the exploratory validity analysis and the reliability analysis and measured on the Likert 5-point scale.

When "Motivation to Transfer" is defined as the learner's desire to transfer, the focus is not supported solely on the zeal itself as the measurement variable. Many studies have introduced the Expectancy Theory presented by Vroom [93] in conceptualizing motivation to transfer [78].

It has been evidenced to use the question "Using the skills learned in this training will improve my work" in the questionnaire items for measuring motivation to transfer in the Noe's study [94]. This questionnaire item means an item that implies the expectation of performance outcome that performance leads to the outcome. In addition, perceptions related expectations, that is, questions such as "how much can work ability be improved by utilizing the contents of training," are used as a questionnaire items for measuring motivation to transfer in Liebermann and Hoffmann's research [95]. These assume higher levels of various expectations, higher aspiration for transition, that is, the linear relationship between expectations and aspirations [84]. Gegenfurtner et al. [78] offer "learners' aspirations and wills of transfer", "self-efficacy", "emotional state", "awareness of usefulness", and "will of autonomous execution" through putting together measurement items from researchers associated with transfer motivation.

Kirwan and Birchall [85] define the transfer intention in the model of learning transfer as "the intent to continuously make efforts to apply educated skills and knowledge to the field". There is "I feel very good when I think about providing new lessons to my work" in the example question item. We apply the definition of transfer intention in the model of learning transfer of Kirwan and Birchall [85], that is, "the intent to continuously make efforts to apply educated skills and knowledge to the field".

The questionnaire items for measuring the variable are based on Hwang's transfer intention-related questionnaire items [92], which is also based on Holton II et al.'s model [75] and modified to be suitable for 3-7-year-old technology-based SMEs. Also, four items suitable for the measurement variables of the latent variables are selected through the exploratory validity analysis and the reliability analysis and measured on the Likert 5-point scale.

Table 1 shows the demographic data of the samples. Table 1 shows that most of the participants were males $(77.9 \%)$, aged between 40 to 49 years old (36.5\%), Bachelor's degree holders $(61.0 \%)$, CEO category (69.4\%), Startup Experience less than four years (58\%), and annual sales of less than 500 million won $(64.1 \%)$.

\subsection{Common Method Bias Solution}

It is fundamental to design the study based on research intents and to measure the variables in a robust way since it is unavoidable to measure latent variables in empirical studies. When a researcher measures dependent variables as well as independent variables of the model with a common method such as a survey, common method bias happens, which hampers the validity of the study. Common method bias is referred to as the error that is attributable to respondents' psychological intention of being consistent and being socially good when answering the questionnaire, which uses the same measurement tools and respondents to measure dependent variables and independent variables. This bias may lead to distort the results of the study in such a way that the levels of relationships among variables increase or decrease, driven by the lower validity of the constructs [96]. 
Table 1. Overview of sample $(\mathrm{N}=860)$.

\begin{tabular}{|c|c|c|c|}
\hline \multicolumn{2}{|c|}{ Respondent Profile } & \multirow{2}{*}{$\begin{array}{c}\text { Numbers } \\
670\end{array}$} & \multirow{2}{*}{$\begin{array}{c}\text { Percentage } \\
77.9\end{array}$} \\
\hline Condor & Male & & \\
\hline Gender & Female & 190 & 22.1 \\
\hline \multirow{5}{*}{ Age } & $20 \sim 29$ years old & 60 & 7.0 \\
\hline & $30 \sim 39$ years old & 276 & 32.1 \\
\hline & $40 \sim 49$ years old & 315 & 36.5 \\
\hline & $50 \sim 59$ years old & 167 & 19.4 \\
\hline & $>60$ years old & 42 & 4.9 \\
\hline \multirow{5}{*}{ Education $^{1}$} & High school graduate & 51 & 5.9 \\
\hline & Associate's Degree & 55 & 6.4 \\
\hline & Bachelor's degree & 523 & 61.0 \\
\hline & Master's Degree & 173 & 20.1 \\
\hline & Doctor's Degree & 57 & 6.6 \\
\hline \multirow{6}{*}{ Position } & CEO & 596 & 69.4 \\
\hline & Executives & 82 & 9.5 \\
\hline & Director & 74 & 8.6 \\
\hline & Manager & 38 & 4.4 \\
\hline & Assistant Manager & 49 & 5.7 \\
\hline & Team Member & 21 & 2.4 \\
\hline \multirow{5}{*}{ Startup Experience } & None & 79 & 9.2 \\
\hline & $1 \sim 2$ years & 28 & 3.3 \\
\hline & $3 \sim 4$ years & 392 & 45.5 \\
\hline & $5 \sim 6$ years & 295 & 34.3 \\
\hline & $>7$ years & 66 & 7.7 \\
\hline \multirow{5}{*}{ Area } & Seoul & 304 & 35.3 \\
\hline & Gyeonggi, Gangwon & 106 & 12.3 \\
\hline & Daejeon, Chungcheong & 109 & 12.7 \\
\hline & Jeonju, Jeolla & 129 & 15.0 \\
\hline & Busan, Gyeongsang & 212 & 24.7 \\
\hline \multirow{8}{*}{ Annual sales } & $<100$ million won & 206 & 24.0 \\
\hline & 100 million $\sim 500$ million won & 345 & 40.1 \\
\hline & 500 million $\sim 1$ billion won & 140 & 16.3 \\
\hline & 1 billion $\sim 1.5$ billion won & 68 & 7.9 \\
\hline & 1.5 billion $\sim 2$ billion won & 23 & 2.7 \\
\hline & 2 billion $\sim 2.5$ billion won & 21 & 2.4 \\
\hline & 2.5billion $\sim 3$ billion won & 12 & 1.4 \\
\hline & $>3$ billion won & 45 & 5.2 \\
\hline & Sum & 860 & 100.0 \\
\hline
\end{tabular}

\footnotetext{
${ }^{1}$ The educational background is 1 missing value and the total number of samples is 859 .
}

It is not desirable, however, to avoid self-reporting surveys considering the merits of such self-reporting tools. The best option to solve Common Method Bias can be to apply different measurement methods for each variable as well as different respondents, which can be impractical in the real world. More practically, the next alternatives lie in the processes of research design, questionnaire design, and statistical analysis to manage common method bias [96].

Despite the risk of bias from self-reporting tools, there exist circumstances where self-reporting questionnaire should be inevitably accepted. The first such case comes from the lines of sights from a particular respondent following one's past actions and one's future intents as well. Second, we should ask the respondents to answer self-reporting surveys when measuring one's psychological status such as attitudes towards jobs, motivation, tensions etc. Lastly, we can rely on self-reporting tools to check respondents' awareness of variables related to external environments $[96,97]$. Such scholars as Campbell [98] and Spector [99] have raised fundamental questions about the validity of self-reporting 
tools, but others are in favor in the sense the validity of constructs from self-reporting questionnaire is superior to other methods [96,100-104].

With an aim to reduce the common method bias from the self-reporting survey, this research has taken several steps. First, we took ex ante remedies in the research design, questionnaire development, and data collection to minimize the common method bias. In order to reduce the likelihood of the consistency motive according to Peterson [105], we improved the brevity, relevance, clarity, specificity, and objectivity of questions to the level possible.

Second, we deployed ex post remedy to test the confirmatory factor analysis (CFA), one of the techniques for detecting multitrait-multimethod matrix (MTMM) following Campbell and Fiske [106] since the variables in the research are latent. Campbell and Fiske [106] suggested that there exist errors in the measurements that heterotrait-homomethod correlation is larger than heterotrait-heteromethod correlation under the condition of convergent validity [96]. Thus, we reduced common method bias among latent variables in the self-reporting survey by testing the convergent validity of CFA model.

\section{Results}

\subsection{Verification of Validity and Reliability of Measurement Model}

A confirmatory factor analysis is used for the validity analysis of the measurement model. The CFA (confirmative factor analysis) can resolve the shortcomings of ERA (exploratory factor analysis) such as the assumptions that all factors are not correlated in the case of orthogonal rotation, all factors are correlated in the case of quadratic rotation, and all measurement variables are loaded on all factors. In addition, it has the advantage of modeling researchers' hypotheses about factor structures and verifying whether or not the hypotheses are supported by actual data from the perspective of model's goodness-of-fit or suitability [107].

In addition, MTMM (multitrait-multimethod matrix), which measures multiple traits in multiple methods is used to overcome the limitations of the measurement method of the survey in the statistical analysis phase, by utilizing the CFA model as Campbell and Fiscke [106] argued. To confirm the conditions for the validation test of latent variables, the Concept Reliability and AVE (Average Variance Extract) is calculated, and Cronbach's Alpha value is also calculated to confirm the reliability as shown in Table 2.

Concentration or convergent validity is to assess "whether there is a relatively high correlation, which is consistency, among the questions measured under the same concept", and factor loading values, or factor loading is reviewed first as the criteria for verification. Since Fornell et al. [108] presented 0.7 and Bagozzi and Yi [109] presented 0.5 as a standardized loading value that shows factor loading, at least 0.5 or more or 0.7 or more of factor loading is desirable [107].

Prior to the assessment of specific validity, the figures in the key GFI (goodness-of-fit) indices for the component model at the bottom of Table 1 show that most conformity indices are relatively good, since SRMR $(=0.037)$ is less than 0.05 , GFI $(=0.914)$, IFI $(=0.954)$, and CFI $(=0.954)$ are more than 0.9 , and AGFI $(0.890)$ is also close to 0.9 . Therefore, it indicates that there is no problem with the convergent or concentration validity.

As shown in Table 1, the factor loading of each latent variable is found to be 0.6 or higher. Each latent variable in the measurement model has an AVE value of 0.6 or higher, and the value of Construct Reliability, which is the result of Bootstrapping (the number of Bootstrap samples: 500) is more than 0.8 indicating that there is the convergent or discriminant validity among the latent and the measurement variables. In addition, since the Cronbach's Alpha values that have been verified for reliability are all 0.8 or higher, the measurement models of latent variables are highly reliable. 
Table 2. Latent variable confirmatory analysis and Cronbach's alpha.

\begin{tabular}{|c|c|c|c|c|c|}
\hline $\begin{array}{c}\text { Latent } \\
\text { Variable }\end{array}$ & Observed Variable & $\begin{array}{c}\text { Factor } \\
\text { Loading }\end{array}$ & $\begin{array}{l}\text { Construct } \\
\text { Reliability }\end{array}$ & AVE & $\begin{array}{c}\text { Cronbach's } \\
\text { Alpha }\end{array}$ \\
\hline \multirow{6}{*}{$\begin{array}{l}\text { Learner } \\
\text { Readiness }\end{array}$} & Learner Readiness 1 & 0.732 & \multirow{6}{*}{0.929} & \multirow{6}{*}{0.688} & \multirow{6}{*}{0.883} \\
\hline & Learner Readiness 2 & 0.782 & & & \\
\hline & Learner Readiness 3 & 0.679 & & & \\
\hline & Learner Readiness 4 & 0.670 & & & \\
\hline & Learner Readiness 5 & 0.824 & & & \\
\hline & Learner Readiness 6 & 0.827 & & & \\
\hline \multirow{7}{*}{$\begin{array}{c}\text { Perceived } \\
\text { Content } \\
\text { Validity }\end{array}$} & Perceived Content Validity 1 & 0.787 & \multirow{7}{*}{0.952} & \multirow{7}{*}{0.741} & \multirow{7}{*}{0.929} \\
\hline & Perceived Content Validity 2 & 0.842 & & & \\
\hline & Perceived Content Validity 3 & 0.836 & & & \\
\hline & Perceived Content Validity 4 & 0.783 & & & \\
\hline & Perceived Content Validity 5 & 0.818 & & & \\
\hline & Perceived Content Validity 6 & 0.825 & & & \\
\hline & Perceived Content Validity 7 & 0.772 & & & \\
\hline \multirow{3}{*}{ Self-Efficacy } & Self-Efficacy 1 & 0.823 & \multirow{3}{*}{0.927} & \multirow{3}{*}{0.808} & \multirow{3}{*}{0.854} \\
\hline & Self-Efficacy 2 & 0.768 & & & \\
\hline & Self-Efficacy 3 & 0.853 & & & \\
\hline \multirow{4}{*}{$\begin{array}{c}\text { Transfer } \\
\text { Intention }\end{array}$} & Transfer Intention 1 & 0.821 & \multirow{4}{*}{0.963} & \multirow{4}{*}{0.868} & \multirow{4}{*}{0.929} \\
\hline & Transfer Intention 2 & 0.892 & & & \\
\hline & Transfer Intention 3 & 0.916 & & & \\
\hline & Transfer Intention 4 & 0.878 & & & \\
\hline \multicolumn{6}{|c|}{$\mathrm{SRMR}^{1}=0.037, \mathrm{GFI}^{2}=0.914, \mathrm{IFI}^{3}=0.954, \mathrm{AGFI}^{4}=0.890, \mathrm{CFI}^{5}=0.954$} \\
\hline
\end{tabular}

${ }^{1}$ Standardized Root Mean squared Residual ${ }^{2}$ Goodness of Fit Index. ${ }^{3}$ Incremental Fit Index. ${ }^{4}$ Adjusted Goodness of Fit Index. ${ }^{5}$ Comparative Fit Index.

Table 3 is for the correlation coefficient matrix and discriminative validity among latent variables. If the square root of AVE is greater than the correlation coefficient among the potential variables, it is considered to have the discriminant validity [107]. In Table 2, for the matrix of latent variables' correlation coefficient, the square root value of the average variance extracted (AVE) is greater than the correlation coefficient among latent variables, indicating that there is a discriminant validity.

Table 3. Correlation analysis and discriminant validity.

\begin{tabular}{|c|c|c|c|c|}
\hline & $\begin{array}{c}\text { Learner } \\
\text { Readiness }\end{array}$ & $\begin{array}{l}\text { Perceived Content } \\
\text { Validity }\end{array}$ & Self-Efficacy & $\begin{array}{l}\text { Square Root } \\
\text { of AVE }\end{array}$ \\
\hline Learner Readiness & & & & 0.829 \\
\hline Perceived Content Validity & $0.669 * *$ & & & 0.861 \\
\hline Self-Efficacy & $0.536^{* *}$ & $0.561^{* *}$ & & 0.899 \\
\hline Transfer Intention & $0.571^{* *}$ & $0.783^{* *}$ & $0.578^{* *}$ & 0.932 \\
\hline
\end{tabular}

\subsection{Hypothesis Verification}

The structural equation model (SEM) is used to test the proposed hypothesis in this study. SEM formalizes the structural relationship among causal variables in the area of interest as an item of a series of linear equations. Also, it is called the causal model or covariance structure model [107]. 
In order to obtain a solution, such as estimates of parameters included in the SEM and the associated major statistics, the Analysis of Measurement Structures (AMOS) 23.0 software is applied.

First, looking at the goodness of fit of the optimal research model analyzed, the fitness criteria are $\chi^{2} /$ d.f. $\leq 2$, SRMR $\leq 0.05$, GFI $\geq 0.9$, IFI $\geq 0.9$, AGFI $\geq 0.9$, and CFI $\geq 0.9$ [107]. Correlation is additionally set with reference to the modification indices (M.I.) in order to modify the structural model that meets these criteria. The rules of model modification have made correlations between measurement errors that belong to the same latent variable, or structural errors that have no causal relationship between latent variables.

Goodness-of-fit indices of this modified structural model are $\chi^{2}=301.506$ (d.f. $=153$ ), $\chi^{2} /$ d.f. $=1.971$, SRMR $=0.031$, GFI $=0.967$, IFI $=0.988$, AGFI $=0.955$, CFI $=0.988$, which satisfies the recommended criteria, and does not cause any problem in analyzing the structural model. Table 4 shows the results of the SEM analysis of the research model derived from this study.

Table 4. Path analysis of structural model and hypothesis verification.

\begin{tabular}{|c|c|c|c|c|}
\hline Hypothesis & Path & $\operatorname{SMC}(\mathbf{R} 2)$ & $\begin{array}{c}\text { Path } \\
\text { Coefficient } \\
\text { (C.R.) }\end{array}$ & $\begin{array}{l}\text { Hypothesis } \\
\text { Verification }\end{array}$ \\
\hline Hypos. 1 & Learner readiness $\rightarrow$ Transfer intention & \multirow{3}{*}{0.659} & $\begin{array}{c}0.020 \\
(0.378)\end{array}$ & reject \\
\hline Hypos. 3 & Self-efficacy $\rightarrow$ Transfer intention & & $\begin{array}{c}0.185^{* * *} \\
(5.014)\end{array}$ & support \\
\hline Hypos. 4 & $\begin{array}{c}\text { Perceived content validity } \rightarrow \text { Transfer } \\
\text { intention }\end{array}$ & & $\begin{array}{l}0.662 * * * \\
(14.712)\end{array}$ & support \\
\hline Hypos. 2 & Learner readiness $\rightarrow$ Self-efficacy & \multirow{2}{*}{0.377} & $\begin{array}{l}0.352 * * * \\
(5.448)\end{array}$ & support \\
\hline Hypos. 5 & Perceived content validity $\rightarrow$ Self-efficacy & & $\begin{array}{c}0.336^{* * * *} \\
(7.206)\end{array}$ & support \\
\hline \multicolumn{5}{|c|}{ SRMR $=0.031$ GFI $=0.967, \mathrm{IFI}=0.988, \mathrm{AGFI}=0.955, \mathrm{CFI}=0.988$} \\
\hline
\end{tabular}

The result of structural model path analysis shows Squared Multiple Correlations (SMC) of transfer intention, which is explained by learner readiness, perceived content validity, and self-efficacy, is $65.9 \%$ and SMC of self-efficacy explained by learner readiness and perceived content validity is $37.7 \%$. The result of structural model path analysis shows that the Critical Ratio value $(0.378)$ is less than 1.96 at $95 \%$ level as shown in Table 3, rejecting hypothesis 1 "Learner readiness has effects on transfer intention".

Hypothesis 2 "Learner readiness has effects on self-efficacy" is supported when the Critical Ratio value is greater than the $95 \%$ level value of $1.96(5.448)(p<0.001)$. The correlation coefficient is 0.352 , which can be interpreted that the higher the learner's readiness, the higher the self-efficacy.

Hypothesis 3 "Self-efficacy has effects on transfer intention" is supported when the Critical Ratio value is greater than the $95 \%$ level value of 1.96 (5.014) $(p<0.001)$. The correlation coefficient is 0.185 , indicating that the higher the self-efficacy, the higher the transfer intention.

Hypothesis 4 "Perceived content validity has effects on transfer intention" is supported when the Critical Ratio value is greater than the 95\% level value of $1.96(14.712)(p<0.001)$. It can be understood that the higher the perceived content validity, the higher transfer intention, as the correlation coefficient is 0.662 .

Hypothesis 5 "Perceived content validity has effect on self-efficacy" is supported when the Critical Ratio value is greater than the $95 \%$ level value of $1.96(7.206)(p<0.001)$. The correlation coefficient is 0.336 , indicating that the higher the perceived content validity, the higher the self-efficacy.

The above analysis shows that the perceived content validity among the significantly shown correlation coefficients is a factor with a relatively high effect coefficient on the degree of transfer 
intention, and it is understood that learners have a high degree of acceptance which the training course is consistent with the actual work and the relevant practices are realistic for increasing sales.

Bootstrap is used for verification of the significance of indirect effects of self-efficacy to verify the hypothesis that a self-efficacy has mediating effects on the relationship between learner readiness and transfer intention as well as the perceived content validity and transfer intention. Bootstrap is a method of re-extracting and analyzing samples based on the samples to be analyzed, and then combining them again to estimate the final statistics. This study uses 500 Bootstrap samples, Percentile Confidence Intervals: 95, and Bias-corrected Confidence Intervals: 95 through AMOS Bootstrap Maximum Likelihood.

As shown in Table 5, the $p$-value(0.004) of indirect effect (0.05) of hypothesis 6 "self-efficacy has mediating effects on learner readiness and transfer intention" is less than the significance level of $1 \%$ and can be supported. In addition, the $p$-value (0.004) of indirect effect (0.064) for Hypothesis 7 "self-efficacy has mediating effects on the perceived content validity and transfer intention" is less than the significance level of $1 \%$ and can be supported.

Table 5. Verification of significance of indirect effect (mediating effect).

\begin{tabular}{ccccc}
\hline & \multicolumn{2}{c}{ Learner Readiness } & \multicolumn{2}{c}{ Perceived Content Validity } \\
\cline { 2 - 5 } & Indirect Effect & $p$-Value & Indirect Effect & $p$-Value \\
\hline Transfer intention & $0.050^{* *}$ & 0.004 & $0.064^{* *}$ & 0.004 \\
\hline
\end{tabular}

The total direct and indirect effects of the latent variables in this study are summarized in Table 5. As seen in Table 6, the coefficient of total effect in relation to the transfer intention is 0.754 and $p$-value is 0.004 , which are less than significance level of $1 \%$. Coefficient of direct effect is 0.689 and $p$-value 0.004 is less than the significance level of $1 \%$. Also, the coefficient of indirect effect is 0.064 and $p$-value 0.004 is less than $1 \%$. Thus, it can be confirmed that the perceived content validity is not only directly effective in the transfer intention, but also has a partial mediating effect through self-efficacy.

Table 6. Direct effect and indirect effect.

\begin{tabular}{cccc}
\hline & \multicolumn{2}{c}{ Total Effect (Direct Effect, Indirect Effect) } \\
\cline { 2 - 3 } & Learner Readiness & Perceived Content Validity & Self-Efficacy \\
\hline Self-efficacy & $0.289^{* *}$ & $0.376^{* *}$ & \\
Transfer intention & $\left(0.289^{* *}, 0.000\right)$ & $\left(0.376^{* *}, 0.000\right)$ & $0.171^{* *}$ \\
& 0.065 & $0.754^{* *}$ & $\left(0.171^{* *}, 0.000\right)$ \\
\hline
\end{tabular}

In the effect of learner readiness on transfer intention, the total effect and direct effect are not statistically significant, with total effect coefficient of 0.065 and $p$-value of 0.295 are greater than a significant level of $5 \%$, a direct effect coefficient of 0.015 and a $p$-value of 0.857 also greater than a significant level of $5 \%$. However, the indirect effects are found to be statistically significant as the coefficient of indirect effects is 0.05 and the $p$-value is 0.004 , less than the significant level of $1 \%$. Thus, the self-efficacy in the learner readiness and relationship with transfer intention can be confirmed as having a fully mediating effect.

\section{Discussion}

This study is brought to assess the effectiveness of the all-fitting Kano-QFD training program, regardless of industry domain, for 3-7-year-old technology-based SMEs. In order to verify the effectiveness of the above program applied to technology-based SMEs, this study utilizes the learning transfer intention model. 
The goal of Kano-QFD training program customized to technology-based SMEs falls on the firms attended achieving more than 5 times sales growth 18 months after after the adoption of the program results onsite. This program is designed to help technology-based SMEs 3-7 years old to boost real business performance progress, not just completing the training program itself.

This paper constructs a research model and conducts an empirical analysis to prove the program effectiveness on the research hypothesis about what influences the transfer intention, that is, the motive to apply training after completing the Kano QFD program targeting the SMEs 860 companies.

This paper set the independent variables as follows: The learner readiness and perceived content validity. Self-efficacy is set mediating variable and dependent variable is transfer intention.

By the empirical test results, the learner readiness does not directly influence the transfer intention, but the effect of the complete mediating occurs with the self-efficacy factor. This paper proved that enhanced self-efficacy by this training leads to the stronger transfer intention regardless of the learner readiness. It also proved that perceived content validity affects the direct effect on transfer intention simultaneously with the partial meditating effect through the self-efficacy factor. The direct effects of perceived content validity over transfer intention effect at the CEO and Executive level identically applied to staff level confirm solidly the effectiveness of Kano-QFD training program customized to 3-7-year-old technology-based SMEs. The major cause of this effects comes from the unique training methods of the program whereby the self-leading learner recognizes the process of planning their firm's growth roadmap via interaction with a one-on-one skilled Kano-QFD coach utilizing spreadsheets.

This study, as proposed by Akao [41], has attempted to solve the limitation of previous studies that explained only QFD usage and provided no information about the effectiveness of QFD. This limitation of not presenting QFD effectiveness is similarly pointed out in the study of Franceschini and Terzago [54]. A few studies have tried to analyze the feasibility of application results only by presenting application cases of QFD. This research verifies the effectiveness of QFD after its comprehensive application to technology-based SMEs in various industries, which differentiates this study from the existing ones since the previous studies offer only a single case in the single industry in order to overcome the limitation $[41,54]$ of the verification absence of the effectiveness of QFD.

We also applied Kano QFD as a means to solve the limitation of traditional QFD, presented by Sivasamy et al. [51]. Traditional QFD analysis has difficult questions to understand customer needs accurately [55] as explained as the shortcomings of QFD [43]. We have combined QFD with Kano's Model for customer satisfaction to accurately understand customer requirements.

Hypothesis 1, "A learner readiness has effects on transfer intention," has been rejected in this study. This result differs from Rowold [82]'s claim. He argued that a participation in training will improve job outcomes in the future if learners are motivated to apply the content of the training to their work when they enter their work environment. The reason for rejecting Hypothesis 1 can be interpreted by the fact that some participants in this study participated in the training to meet the requirements of the government grants without much expectation in prior. Hypothesis 2, "A learner readiness has effects on self-efficacy," has been accepted as statistically significantly, which is consistent with the study of Kirwan and Birchall [85]. Hypothesis 3, "A self-efficacy has effects on transfer intention," has been accepted statistically significantly. The result is consistent with the studies in Holton III et al. [83], Machine and Fogarty [87], Axtell, et al. [88], and Al-Eisa et al. [89].

The results of paper deliver several significant contributions. First, this study verifies the literatures empirically with the fact that this Kano-QFD program is powerful enough to resolve the fatal flaws of 3-7-year-old technology-based SMEs, struggling with pended sales volume and big chasms to scale-up. It also empirically proves that this Kano-QFD program is effective to motivate CEOs and executives to adopt Kano QFD to real fields regardless of industry domains. The big breakthrough of this study's achievement falls to the development of the Kano-QFD's applicability to 3-7-year-old technology-based SMEs regardless of industry domain unlike the previous studies focusing only on individual industries, or ones concerning companies with sufficient QFD-related human resources and sufficient financial resources, such as large companies. The program this study deals with benefits 
this type of company finding loopholes against pended sales situations such as the Valley of Death. Second, this study contributes significantly to the literature by showcasing real cases of effective Kano-QFD application evaluated by transfer intention model with 3-7-year-old technology-based SMEs. This paper answers the calls of scholars who pointed out the crucial limitations in the previous QFD studies, such as (1) the absence of information sharing about the effects of applied QFD [31], (2) the shortcoming [31,54] of case studies, and (3) research done in some regional areas despite QFD being utilized worldwide $[29,30]$. Third, another pivotal contribution of this paper lies in the fact that we focus on SMEs, which is the white space in Kano-QFD research. Most SMEs, which account for $80 \%$ of the world economy [2], have not used QFD as a tool for corporate growth due to financial constraints to implement the QFD and Kano Model. We were fortunate to initiate Kano-QFD programs targeting SMEs in Korea, which bore the fruits of Kano-QFD being effectively studied in technology-based SMEs. This research contributes to providing very important implications for the education and training planners in the government and related organizations leading the technology entrepreneurship policy.

However, this study shows the following research limitations despite the above contributions. The first limitation results from its research design. Learner readiness can be more accurately measured by surveys prior to the program launch avoiding learner's common method bias. This study was not able to conduct the prior surveys since such surveys might be used as a screening tool that is not compliant with the fairness principle, particularly crucial in a policy-driven program by the Ministry of SMEs and Startups and Korea Institute of Start-up and Entrepreneurship Development. The second limitation falls on failing to source out more specific variables, which are survey questions in transfer intention considered by the previous studies. For example, Kirwan and Birchall [85] divide the training design characteristics into the perceived content validity and the practice-oriented design, and divide opportunities for utilization, and present the measurement variables for this in consideration of the factors before learning and applying. However, this study only takes the perceived content validity as the training design characteristics in consideration. The future study needs to develop not only more specific measuring variables as to transfer intention, but also to add up more surveying questions to measure these specific variables. The third limitation can be the study samples consisting of government-chosen participants. It is desirable to expand the samples in non-governmental programs as well in the subsequent studies. Fourth, this study considers transfer intention as the only dependent variable due to the limitation of being a government program, whereby surveying the effect of learning transfer after the program requires asking for an additional, immense budget. This study also did not undertake the task of adding environmental factors in the survey, one of three types of factors affecting to the transfer intention, suggested by Baldwin and Ford [27]. This opens up a following research topic on difficulties of selecting measuring survey question due to the domain diversity and age of participating SMEs. This study will continue to research the learning transfer effect when Kano QFD is applied to real tasks of business three to six months after the completion of program and regarding task environmental factors.

\section{Conclusions}

We present an education and training program that can comprehensively incorporate QFD, which has been used only for individual companies in some industries, into technology-based SMEs in various industries. This program will be leveraged as a one of the measures to solve the sales and net profits stagnation of 3-7-year-old technology-based SMEs in the stage of the initial growth period. We researched the effectiveness of these programs. As a result of empirical analysis, it is proven that the Kano QFD program for 3-7-year-old technology-based SMEs is effective.

Briefly presenting a Kano QFD program that can be applied to technology-based SMEs of various industries has the following features. First, the structure of Kano QFD program designed for the technology-based SMEs 3-7 years old consists of three steps, which are the product concept planning stage, VOC implementation stage, and the product specification confirmation stage. 
In the product concept planning stage, 3-7-year-old technology-based SMEs should be able to check the entry market that can achieve the sales of 5 times or 10 times the current sales as a step for preparing the necessary elements before executing Kano QFD. In particular, it is necessary for technology-based SMEs to have a strategic pivoting direction for products or services that can satisfy customer needs more discriminatively than competitors in order to have sales momentum, and also it is important to target a market for direct competitors or alternatives while having access to higher customer delight factors than competitors, which Shen et al. [63] emphasized.

The VOC implementation stage is to navigate and analyze the customer's delight element through the Kano questionnaire for the target customers of the selected market in the product concept planning stage. The number of customers for the Kano questionnaire is between 15 and 20 in consideration of Griffin and Hauser's research [110] and the poor internal environment of technology-based SMEs 3-7 years old.

The product specification confirmation stage is to select the voice of the preferentially concentrated customers by comparing the in-house ability and the ability of the competitor, which is to satisfy the customer's delight element, and to find the preferred investment characteristic of the product or service that satisfies the customer's delight element.

The second feature is that Kano QFD has a pre-trained coach to overcome the limitations of SMEs that do not have sufficient financial resources and specialists in the company to run QFD and Kano Model. One coach is assigned to each participant in the education and training program.

The third feature is that the qualification of participant of technology-based SMEs is limited to representative director as much as possible who plays an important role in determining the strategy and direction of SMEs.

The fourth feature is that the entire process from the planning stage of the product concept to the product specification confirmation stage is entered on the worksheet in order to facilitate communication between participants of SMEs who do not have a good understanding of Kano QFD and pre-trained coaches and also to complete the Kano QFD process within a total of $16 \mathrm{~h}$ over two days. Thus, it is designed so that the current state of the technology-based SMEs 3-7 years old and future strategies can be objectively examined.

The fifth feature is that the modified grid of Timko's classification table is utilized in order to select the demand factors of priority consideration customers by concretely scoring the customer delight factors instead of the existing Timko's classification chart of quality characteristics [111]. This classification table can be weighted more finely, even in an attractive and one-dimensional quality element while there is a limit to comprehensively calculate the attractive quality element with a weight of 5 points, and the one-dimensional quality element with a weight of 4 points in the conventional Timko's Analysis.

Author Contributions: Conceptualization, Y.H.; methodology, Y.H.; investigation, Y.H., Y.-S.Y., and M.-S.K.; writing—original draft preparation, Y.H., Y.-S.Y., M.-S.K., and Y.K.; writing—review and editing, Y.K. All authors have read and agreed to the published version of the manuscript.

Funding: This research received no external funding.

Conflicts of Interest: The authors declare no conflict of interest.

\section{References}

1. Gherardini, F.; Renzi, C.; Leali, F. A systematic user-centred framework for engineering product design in small- and medium-sized enterprises (SMEs). Int. J. Adv. Manuf. Technol. 2017, 91, 1723-1746.

2. Jutla, D.; Bodorik, P.; Dhaliqal, J. Supporting the E-business Readiness of Small and Medium-Sized Enterprises: Approaches and Metrics. Internet Res. 2002, 12, 139-164.

3. Birch, D.L. Job Creation in America: How Our Smallest Companies Put the Most People to Work; Free Press: New York, NY, USA, 1987.

4. Kane, T. The Importance of Startups in Job Creation and Job Destruction; Kauffman Foundation: Kansas City, MO, USA, 2010. 
5. Science and Technology Policy Institute. Global Entrepreneurship Index and Its Implications on Korean Start-up Environment. Res. Policy 2014, 8.

6. Storey, D.J.; Tether, B.S. New Technology-Based Firms (NTBFs) in Europe. A European Innovation Monitoring System study for The Innovation Programme; Directorate General XIII of the European Commission: Luxembourg, 1996; EIMS Publication No. 31.

7. Rickne, A.; Jacobsson, S. New Technology-Based Firms in Sweden-A study of their direct impact of industrial renewal. Econ. Innov. New Technol. 1999, 8, 197-223.

8. Ministry of SMEs and Startups. 2018 Startup Company Survey; Korea Institute of Start-up and Entrepreneurship Development: Daejeon, Korea, 2019.

9. Korea Institute of Start-up and Entrepreneurship Development. Analysis of Survival Rate and Job Creation Effect of Startup Companies; Korea Institute of Start-up and Entrepreneurship Development: Daejeon, Korea, 2018.

10. Kim, M.S.; Yang, Y.S.; Hwangbo, Y. The Correlation Influences by the Quality of Product Pivoting Boot Camp and its level of Training Satisfaction on the Applying Will to Their Real Business of High-tech Ventures in the Early Stage of Growth. Asia-Pac. J. Bus. Ventur. Entrep. 2018, 13, 37-46.

11. Griffin, A. Evaluating QFD's Use in US Firms as A Process for Developing Products. J. Prod. Innov. Manag. 1992, 9, 171-187.

12. Chen, L.H.; Ko, W.C. Fuzzy Approaches to Quality Function Deployment for New Product Design. Fuzzy Sets Syst. 2009, 160, 2620-2639.

13. Lim, H.-J.; Yu, Y.-M.; Won, S.-H. A Value-Based Education Service Design Using Quality Function Deployment (QFD). Prod. Oper. Manag. 2016, 27, 127-148.

14. Ramezanian-Pournasir, M. Expansion of performance quality. Automot. Ind. J. 2007, 106, 30-34. (In Persian)

15. Hauser, J.R.; Clausing, D. The House of Quality; Harvard Business Review; Harvard Business Publishing: Brighton, MA, USA, 1988.

16. Zhou, Z.; Xiao, Z.; Liu, Q.; Ai, Q. An analytical approach to customer requirement information processing. Enterp. Inf. Syst. 2013, 7, 543-557.

17. Tai, W.-T. Effects of training framing, general self-efficacy and training motivation on trainees' training effectiveness. Pers. Rev. 2006, 35, 51-65.

18. Kirkpatrick, D.L. Evaluation Training Programs: The Four Levels; Berrett-Koehler: San Francisco, CA, USA, 1994.

19. Chang, D.-J. A Study on the Effectiveness of Education and Training in the Military Spirit Leader Program. J. Spirit. Ment. Force Enhanc. 2019, 58, 149-189.

20. Clement, R.W. An Empirical Test of the Hierarchy Theory of Training Evaluation. Ph.D. Dissertation, Department of Management, Michigan State University, East Lansing, MI, USA, 1978.

21. Fromkin, H.L.; Brandt, J.; King, D.C.; Sherwood, J.J.; Fisher, J. An evaluation of human relations training for police. Cat. Sel. Doc. Psychol. 1975, 5, 206-207.

22. Latham, G.P.; Wexley, K.N.; Purcell, E.D. Training managers to minimize rating errors in the observation of behavior. J. Appl. Psychol. 1975, 60, 550-555. [CrossRef]

23. Noe, R.A.; Schmitt, N. The Influence of Trainee Attitudes on Training Effectiveness: Test of a Model. Pers. Psychol. 1986, 39, 497-523. [CrossRef]

24. Magjuka, R.J.; Baldwin, T.T. Team-based Employee Involvement Programs: Effects of Design and administration. Pers. Psychol. 1991, 44, 793-812. [CrossRef]

25. Foxon, M.J. Process Approach to the Transfer of Training: Part 1: The Impact of Motivation and Supervisor Support on Transfer Maintenance. Australas. J. Educ. Technol. 1993, 9, 130-143.

26. Ajzen, I. The theory of planned behavior. Organ. Behav. Hum. Decis. Process. 1991, 50, 179-211.

27. Baldwin, T.T.; Ford, J.K. Transfer of Training: A Review and Directions for Future Research. Pers. Psychol. 1988, 41, 63-105. [CrossRef]

28. Salas, E.; Milham, L.M.; Bowers, C.A. Training Evaluation in the Military: Misconceptions, Opportunities, and Challenges. Mil. Psychol. 2003, 15, 3-16. [CrossRef]

29. Prasad, B. Review of Q. F. D. and related deployment techniques. J. Manuf. Syst. 1998, 17, 221-234.

30. Sullivan, L.P. Quality Function Deployment. Qual. Prog. 1986, 19, 39-50.

31. Cristiano, J.; Liker, J.K.; White, C.C., III. Customer-Driven Product Development through Quality Function Deployment in the U.S. and Japan. J. Prod. Innov. Manag. 2000, 17, 286-308. 
32. Wasserman, G.S. On how to prioritize design requirements during the QFD planning process. IIE Trans. 1993, 25, 59-65. [CrossRef]

33. Bicknell, B.A.; Bicknell, K.D. The Road Map to Repeatable Success-Using QFD to Implement Change; CRC Press Inc.: Boca Raton, FL, USA, 1995; p. 345.

34. Guinta, L.R.; Praizler, N.C. The QFD Book: The Team Approach to Solving Problems and Satisfying Customers through Quality Function Deployment; AMACOM: New York, NY, USA, 1993.

35. Runte, M. Customer Driven Computer Assisted Product Development System for Quality Function Deployment; Project Report; The University of New South Wales: Sydney, Australia, 1997.

36. Park, J. A Study on the Test and Evaluation Technique by Applying QFD at Research and Development Stage: Focused on 000mm Self-Propelled Mortar Project. Ph.D. Dissertation, Graduate School, Konkun University, Seoul, Korea, 2019.

37. American Supplier Institute. Quality Function Deployment, Executive Briefing; American Supplier Institute Inc.: Dearborn, MI, USA, 1987.

38. Massa, G.; Gessa, N. QFD for a SME network of the wood sector to improve competitiveness and sustainability. In Proceedings of the International Conference on Sustainable Design and Manufacturing, Chania, Crete, Greece, 4-6 April 2016; Volume 52, pp. 501-511.

39. Tan, K.C.; Shen, X.X. Integrating Kano's Model in the Planning Matrix of Quality Function Deployment. Total Qual. Manag. 2000, 11, 1141-1151. [CrossRef]

40. Jung, Y.-S.; Kang, K.-S. Improvements of logistics service focusing on value factors utilizing QFD. J. Korea Saf. Manag. Sci. 2017, 19, 209-219.

41. Akao, Y. Quality Function Deployment: Integration Customer Requirements into Product Design; Mazur, G.H., Translator; Productivity Press: Cambridge, MA, USA, 1990.

42. Sharma, J.R.; Rawani, A.M.; Barahate, M. Quality function deployment: A comprehensive literature review. Int. J. Data Anal. Tech. Strat. 2008, 1, 78-103. [CrossRef]

43. Kamvysi, K.; Gotzamani, K.; Andronikidis, A.; Georgiou, A.C. Capturing and prioritizing students' requirements for course design by embedding Fuzzy-AHP and linear programming in QFD. Eur. J. Oper. Res. 2014, 237, 1083-1094. [CrossRef]

44. Vinodh, S.; Chintha, S.K. Application of fuzzy QFD for enabling agility in a manufacturing organization: A case study. TQM J. 2011, 23, 343-357. [CrossRef]

45. Sener, Z.; Karsak, E.E. A combined fuzzy linear regression and fuzzy multiple objective programming approach for setting target levels in quality function deployment. Expert Syst. Appl. 2011, 38, 3015-3022. [CrossRef]

46. Andronikidis, A.; Georgiou, A.C.; Gotzamani, K.; Kamvysi, K. The application of quality function deployment in service quality management. TQM J. 2009, 21, 319-333. [CrossRef]

47. Akao, Y.; Mazur, G.H. The leading edge in QFD: Past, present and future. Int. J. Qual. Reliab. Manag. 2003, 20, 20-35. [CrossRef]

48. Devandasan, S.R.; Kathiravan, N.; Thirunavukkarasu, V. Theory and practice of total quality function deployment: A perspective from a traditional pump-manufacturing environment. TQM Mag. 2006, 18, 143-161. [CrossRef]

49. Bouchereau, V.; Rowlands, H. Methods and techniques to help quality function deployment (QFD). Benchmark. Int. J. 2000, 7, 8-20. [CrossRef]

50. Wu, H.-H.; Shieh, J.-I. Applying a markov chain model in quality function deployment. Qual. Quant. 2008, 42, 665-678. [CrossRef]

51. Sivasamy, K.; Arumugam, C.; Devadasan, S.R.; Murugesh, R.; Thilak, V.M.M. Advanced models of quality function deployment: A literature review. Qual. Quant. 2016, 50, 1399-1414. [CrossRef]

52. Akao, Y.; Naoi, T. Survey and Reviews on Quality Function Deployment in Japan. In Proceedings of the International Conference on Quality Control (ICQC), Tokyo, Japan, 20-23 October 1987.

53. Naoi, T.; Ohfuji, T.; Akao, Y. Results of a Questionnaire on the Status of the Use of Quality Deployment; Working Paper; Tamagawa University: Machida, Japan, 1987.

54. Franceschini, F.; Terzago, M. An application of quality function deployment to industrial training courses. Int. J. Qual. Reliab. Manag. 1988, 15, 753-768. [CrossRef]

55. Cristiano, J.J.; Liker, J.K.; White, C.C., III. Key factors in the successful application of quality function deployment. IEEE Trans. Eng. Manag. 2001, 48, 81-95. [CrossRef] 
56. Matzler, K.; Hinterhuber, H.H. How to make product development projects more successful by integrating Kano's model of customer satisfaction into quality function deployment. Technovation 1998, 18, 25-38. [CrossRef]

57. Govers, C.P.M. What and how about quality function deployment (QFD). Int. J. Prod. Econ. 1996, 46-47, 575-585. [CrossRef]

58. Sauerwein, E.; Bailom, F.; Matzler, K.; Hinterhuber, H.H. The Kano model: How to delight your customers. Presented at the IX. International Working Seminar on Production Economics, Innsbruck, Austria, 22-26 February 1996; pp. 313-327.

59. Cohen, L. Quality Function Deployment: How to Make QFD Work for You; Prentice Hall: New York, NJ, USA, 1995.

60. Shahin, A. Integration of FMEA and the Kano Model: An Exploratory Examination. Int. J. Qual. Reliab. Manag. 2004, 21, 731-746. [CrossRef]

61. Kano, N.; Seraku, N.; Takashi, F.; Tsuji, S. Attractive Quality and Must-be Quality. J. Jpn. Soc. Qual. Control 1984, 14, 39-48.

62. Lee, Y.-C.; Sheu, L.-C.; Tsou, Y.-G. Quality function deployment implementation based on Fuzzy Kano model: An application in PLM system. Comput. Ind. Eng. 2008, 55, 48-63. [CrossRef]

63. Shen, X.X.; Tan, K.C.; Xie, M. An integrated approach to innovative product development using Kano's model and QFD. Eur. J. Innov. Manag. 2000, 3, 91-99. [CrossRef]

64. European Commission. Recommendation 2003/361/EC: SME definition. Off. J. Eur. Union 2003, L 124, 36-41.

65. National Legal Information Center. Available online: https://www.law.go.kr (accessed on 21 July 2020).

66. Rozar, N.M.; Razik, M.A.; Zakaria, M.N. Sustainability performance approach in Malaysia's SMEs for Improving Green Supply Chain Management (GSCM); An Application of Quality Function Deployment (QFD). Int. J. Supply Chain Manag. 2019, 8, 993-998.

67. O'Gorman, P.; Morgan, M.; Van Merkom, R. Using QFD to Normalize a Culture of Innovation in an Engineering SME. In Proceedings of the IEEE International Conference on Industrial Engineering and Engineering Management, Macao, China, 15-19 December 2019; pp. 307-310.

68. Hsu, C.-H.; Chang, A.-Y.; Luo, W. Identifying key performance factors for sustainability development of SMEs-integrating QFD and fuzzy MADM methods. J. Clean. Prod. 2017, 161, 629-645. [CrossRef]

69. Tan, B.L.; Forrester, P.L.; Tang, N.K.H. Application of QFD for e-Business planning. Prod. Plan. Control 2004, 15, 802-818. [CrossRef]

70. Barad, M.; Gien, D. Linking improvement models to manufacturing strategies-a methodology for SMEs and other enterprises. Int. J. Prod. 2001, 39, 2675-2695. [CrossRef]

71. Kirkpatrick, D.L. Evaluation of training. In Training and Development Handbook; Craig, R.L., Bittel, L.R., Eds.; McGraw-Hill: New York, NY, USA, 1967; pp. 87-112.

72. Alliger, G.M.; Janak, E.A. Kirkpatrick's levels of training criteria: Thirty years later. Pers. Psychol. 1989, 42, 331-341. [CrossRef]

73. Colquitt, J.A.; LePine, J.A.; Noe, R.A. Toward an integrative theory of training motivation: A meta-analytic path analysis of 20 years of research. J. Appl. Psychol. 2000, 85, 678-707. [CrossRef]

74. Kraiger, K.; Ford, J.K.; Salas, E. Application of cognitive, skill-based, and affective theories of learning outcomes to new methods of training evaluation. J. Appl. Psychol. 1993, 78, 311-328. [CrossRef]

75. Gagne, R.M.; Medsker, K.L. The Conditions of Learning; Harcourt Brace Jovanovich: Fort Worth, TX, USA, 1996.

76. Park, J.-S.; Kim, J.-M. Predictors of the Transfer Intention of the Participants in a Corporate Leadership Training Program. Korean J. Hum. Resour. Dev. Q. 2016, 18, 49-79.

77. Burke, L.A.; Hutchins, H.M. Training Transfer: An Integrative Literature Review. Hum. Resour. Manag. Rev. 2007, 6, 263-296. [CrossRef]

78. Gegenfurtner, A.; Fester, D.; Gallenberger, W.; Lehtinen, E.; Gruber, H. Predicting Autonomous and Controlled Motivation to Transfer Training. Int. J. Train. Dev. 2009, 13, 124-138. [CrossRef]

79. Yamnill, S.; McLean, G.N. Factors Affecting Transfer of Training in Thailand. Hum. Resour. Dev. Q. 2005, 16, 323-344. [CrossRef]

80. Seyler, D.L.; Holton, E.F., III; Bates, R.A.; Burnett, M.F.; Carvalho, M.A. Factors affecting motivation to transfer training. Int. J. Train. Dev. 1998, 2, 2-16. [CrossRef]

81. Kirkpatrick, D.L. Techniques for evaluating training programs. Class. Writ. Instr. Technol. 1996, 1, 119-142.

82. Rowold, J. The Impact of Personality on Training-related Aspects of Motivation: Test of a Longitudinal Model. Hum. Resour. Dev. Q. 2007, 18, 9-34. [CrossRef] 
83. Holton, E.F., III; Bates, R.A.; Ruona, W.E.A. Development of a Generalized Learning Transfer System Inventory. Hum. Resour. Dev. Q. 2000, 11, 333-360. [CrossRef]

84. Park, J.-S. Predictors of the Transfer Intention of the Participants in a Corporate Leadership Training Program. Ph.D. Dissertation, Department of Agricultural and Vocational Education, Seoul University, Seoul, Korea, 2015.

85. Kirwan, C.; Birchall, D. Transfer of Learning from Management Development Programmes: Testing the Holton Model. Int. J. Train. Dev. 2006, 10, 252-268. [CrossRef]

86. Bandura, A. Self-efficacy: Toward a Unifying Theory of Behavioral Change. Psychol. Rev. 1977, 84, 191. [CrossRef] [PubMed]

87. Machin, M.A.; Fogarty, G.J. Perceptions of Training-related factors and Personal Variables as Predictors of Transfer Implementation Intentions. J. Bus. Psychol. 2003, 18, 51-71. [CrossRef]

88. Axtell, C.M.; Maitlis, S.; Yearta, S.K. Predicting Immediate and Longer-term Transfer of Training. Pers. Rev. 1997, 26, 201-213. [CrossRef]

89. Al-Eisa, A.S.; Furayyan, M.A.; Alhemoud, A.M. An Empirical Examination of the Effects of Self-efficacy, Supervisor Support and Motivation to Learn on Transfer Intention. Manag. Decis. 2009, 47, 1221-1244. [CrossRef]

90. Saks, A.M.; Belcourt, M. An Investigation of Training Activities and Transfer of Training in Organizations. Hum. Resour. Manag. 2006, 45, 629-648. [CrossRef]

91. Hwang, J.I.; Gu, J.W. The Effects of Leadership Training Program for the Hospital and Firm. J. Hum. Resour. Manag. Res. 2012, 19, 71-96.

92. Hwang, J.I. Study on the Learning Transfer Effects of Leadership Training Program: For the High Level Managers in Firms and the Physicians in Hospitals. Ph.D. Dissertation, A Seoul School of Integrated Sciences \& Technologies, Seoul, Korea, 2013.

93. Vroom, V.H. Work and Motivation; Wiley: New York, NY, USA, 1964.

94. Noe, R.A. Trainees' Attributes and Attitude: Neglected Influences on Training Effectiveness. Acad. Manag. Rev. 1986, 11, 736-749. [CrossRef]

95. Liebermann, S.; Hoffmann, S. The impact of practical relevance on training transfer: Evidence from a service quality training program for German bank clerks. Int. J. Train. Dev. 2008, 12, 74-86. [CrossRef]

96. Park, W.-W.; Kim, M.S.; Jeong, S.M.; Huh, K.M. Causes and Remedies of Common Method Bias. Korean J. Manag. 2007, 15, 89-133.

97. Podsakoff, P.M.; Organ, D.M. Self-reports in organizational research: Problems and prospects. J. Manag. 1986, 12, 69-82. [CrossRef]

98. Kline, T.J.B.; Sulsky, L.M.; Rever-Moriyama, S.D. Common method variance and specification errors: A practical approach to detection. J. Psychol. 2000, 134, 401-421. [CrossRef] [PubMed]

99. Spector, P.E. Using self-report questionnaires in OB Research: A comment on the use of a controversial method. J. Organ. Behav. 1994, 15, 385-392. [CrossRef]

100. Cole, D.A.; Howard, G.S.; Maxwell, S.E. The effect of mono versus multiple operationalization in construct validation efforts. J. Consult. Clin. Psychol. 1981, 49, 395-405. [CrossRef]

101. Cole, D.A.; Lazarick, D.M.; Howard, G.S. Construct validity and the relation between depression and social skill. J. Couns. Psychol. 1987, 34, 315-321. [CrossRef]

102. Gabbard, C.E.; Howard, G.S.; Dunfee, E.J. Reliability, sensitivity to measuring change, and construct validity of therapist adaptability. J. Couns. Psychol. 1986, 33, 377-386. [CrossRef]

103. Howard, G.S.; Conway, C.G.; Maxwell, S.E. Construct validity of measures of college teaching effectiveness. J. Educ. Psychol. 1985, 77, 187-196. [CrossRef]

104. Howard, G.S.; Maxwell, S.E.; Wiener, R.L.; Boynton, K.S.; Rooney, W.M. Is a behavioral measure the best estimate of behavioral parameters? Perhaps not. Appl. Psychol. Meas. 1980, 4, 293-311. [CrossRef]

105. Peterson, R.A. Constructing Effective Questionnaires; Sage: Thousand Oaks, CA, USA, 2000.

106. Campbell, D.T.; Fiske, D. Convergent and discriminant validation by the multitrait-multimethod matrix. Psychol. Bull. 1959, 56, 81-105. [CrossRef]

107. Kang, H.C. Structural Equation Model Analysis and Application; Liberty Academy: Seoul, Korea, 2019.

108. Fomell, C.; Larcker, D. Evaluating Structural Equation Models with Unobservable Variables and Measurement Error. J. Mark. Res. 1981, 18, 39-50.

109. Bagozzi, R.; Yi, Y. On the evaluation of structural equation models. J. Acad. Mark. Sci. 1988, 16, 74-94. [CrossRef] 
110. Griffin, A.; Hauser, J.R. The Voice of the Customer. Mark. Sci. 1993, 12, 1-27. [CrossRef]

111. Bae, J.-H.; Shin, H.-Y. A Study on the Factor of Satisfaction or Dissatisfaction of e-Learning Using Kano Model and Timko's Customer Satisfaction coefficients. J. Korea Converg. Soc. 2019, 10, 325-333.

(C) 2020 by the authors. Licensee MDPI, Basel, Switzerland. This article is an open access article distributed under the terms and conditions of the Creative Commons Attribution (CC BY) license (http://creativecommons.org/licenses/by/4.0/). 